\title{
Prediction of long-term wind speed and capacity factor using Measure-Correlate-Predict method
}

\author{
Ko, Kyung-Nam* Huh, Jong-Chul** \\ *Multidisciplinary Graduate School Program for Wind Energy, Jeju National \\ University(gnkor2@jejunu.ac.kr), \\ **Faculty of Mechanical System Engineering, Jeju National University(jchuh@jejunu.ac.kr)

\section{측정-상관-예측법을 이용한 장기간 풍속 및 설비이용률의 예측} \\ 고경남*, 허종철** \\ *제주대학교 대학원 풍력특성화협동과(gnkor2@jejunu.ac.kr), ** 제주대학교 기계시스템공학부(jchuh@jejunu.ac.kr)
}

\begin{abstract}
Long-term variations in wind speed and capacity factor $(\mathrm{CF})$ on Seongsan wind farm of Jeju Island, South Korea were derived statistically. The selected areas for this study were Subji, having a year wind data at $30 \mathrm{~m}$ above ground level, Sinsan, having 30-year wind data at $10 \mathrm{~m}$ above ground level and Seongsan wind farm, where long-term CF was predicted. The Measure-Correlate-Predict module of WindPRO was used to predict long-tem wind characteristics at Seongsan wind farm. Each year's CF was derived from the estimated 30-year time series wind data by running WAsP module. As a result, for the 30-year CFs, Seongsan wind farm was estimated to have $8.3 \%$ for the coefficient of variation, $\mathrm{CV}$, and $-16.5 \% \sim 13.2 \%$ for the range of variation, $\mathrm{RV}$. It was predicted that the annual CF at Seongsan wind farm varied within about $\pm 4 \%$.
\end{abstract}

Keywords : 풍력에너지 (Wind energy), 바람데이터 (Wind data), 설비이용률 (Capacity factor, CF), 측정-상관예측 (Measure-Correlate-Predict)

\section{Nomenclature}

$\bar{V}_{\max }:$ The maximum of yearly average wind speeds $[\mathrm{m} / \mathrm{s}]$

$\bar{y}$ : Wind speed averaged over 30 years $[\mathrm{m} / \mathrm{s}]$

$\bar{V}_{\min }:$ The minimum of yearly average

$\sigma:$ Standard deviation wind speeds $[\mathrm{m} / \mathrm{s}]$

Submit date : 2012. 8. 14. Judgment date : 2012. 8. 24. Publication decide date : 2012. 12. 20.

Communication author : Ko, Kyung-Nam(gnkor2@jejunu.ac.kr) 


\section{Introduction}

The importance of development of new and renewable energy needs no further elaboration. Wind energy technology is one of the fastest growing technologies in new and renewable energy. At the end of 2010, total global wind power capacity was approximately $200 \mathrm{GW}$ with the biggest installed capacity of China, followed by United States.1) It is predicted that about 2,500 GW worldwide wind power capacity is expected by 2030, which would correspond to $17 \%$ of total global electricity consumption.2) It is very important to select stronger windy sites in a country for the purpose of producing more electricity. Since wind speed varies from year to year, particular care should be taken to assess wind energy in a given site. Namely, it could have high uncertainties to estimate potential wind energy in a site using the wind data for just one year or less.

Earlier investigations have pointed out that the yearly average wind speed varies from year to year but within $\pm 10 \%$ of the long term mean. However it is more important for the prospective owner of a wind farm to understand the variability in annual $\mathrm{CF}$ than that in yearly average wind speed. Weisser et al. ${ }^{3)}$ showed that in their case study wind velocity significantly fluctuated seasonally and diurnally, which should be considered where specific electricity loads are required. Based on modelling of wind speed data measured from 66 onshore sites across the United Kingdom, Sinden ${ }^{4)}$ reported that the capacity factor was in the range between $24.1 \%$ and $35.7 \%$ for 34 years from 1970 to 2003. Yoreley et al." showed yearly average wind speed varied with years and regions. In Germany and Denmark, the wind index which is an energy delivery index within a certain period, has been analyzed since about 1990, because there is a need to assess wind energy fluctuation with years. ${ }^{6)}$

Jeju Island is known to be one of the windiest regions in South Korea. Although there was some research ${ }^{7,8)}$ on inter-annual variations in wind speed in Jeju Island, no study on variability in $\mathrm{CF}$ has been carried out for the Island. That is because it is very difficult to collect wind data at real wind turbine hub height for a long-term period. However, some researchers have been applying Measure-Correlate-Predict (MCP) method to obtain long-term predicted wind data for more reliable analysis of wind regime.

In this study, the wind data for 30 years at Seongsan wind farm of Jeju Island were predicted using MCP method. This investigation aims to clarify the coefficient of variation and the range of variation for annual $\mathrm{CF}$ as well as annual wind speed at Seongsan wind farm. In addition, the values are compared with those in the United Kingdom to understand the difference in inter-annual variations of $\mathrm{CF}$ between Seongsan and the United Kingdom.

\section{Sites description and method}

Jeju Island is located off the southern coast of main land Korea. Figure 1 shows Jeju Island and locations of three sites for this study, which are all located on eastern 
part of Jeju Island. Seongsan wind farm is situated inland, while the other two sites, Subji and Sinsan, are located near the coastline.

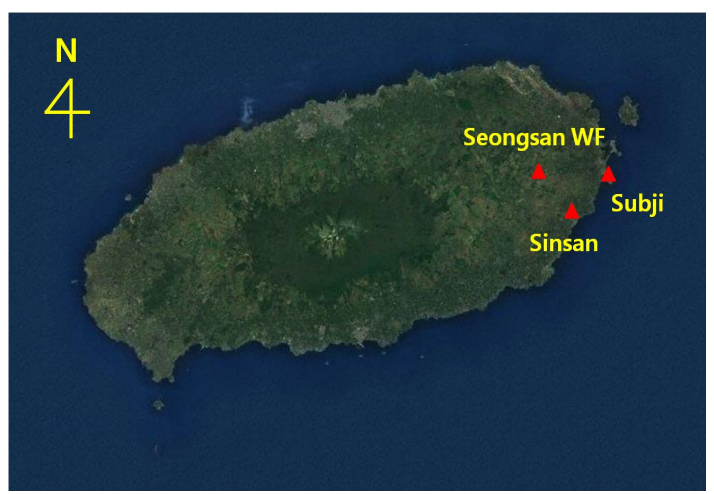

Fig. 1 Jeju Island of South Korea and locations of three sites for this study

WindPRO software that was developed by EMD international A/S of Denmark was used for this study. Roughness map for indicating topographical conditions is presented in Figure 2. Roughness classes were drawn from class 0 corresponding to water area to class 3 corresponding to small town. ${ }^{9}$ Subji site, where hourly wind data for one year of 1998 was collected at $30 \mathrm{~m}$ above ground level, and Seongsan wind farm, where annual CFs are predicted, are also shown in Figure 2.

At Sinsan site of the Figure, there is an Automated Synoptic Observation System (ASOS) which is operated by Korea Meteorological Administration. It has been measuring meteorological data for a long time. The 30-year hourly wind data from 1981 to 2010 was measured at $10 \mathrm{~m}$ above ground level and collected from ASOS. Meteorologists have pointed out that the 30-year wind data is needed to determine long-term values of climate. ${ }^{10)}$ In other words, the reliable conclusion on wind energy at a site can be derived from the analysis on the basis of the 30-year wind data at the site.

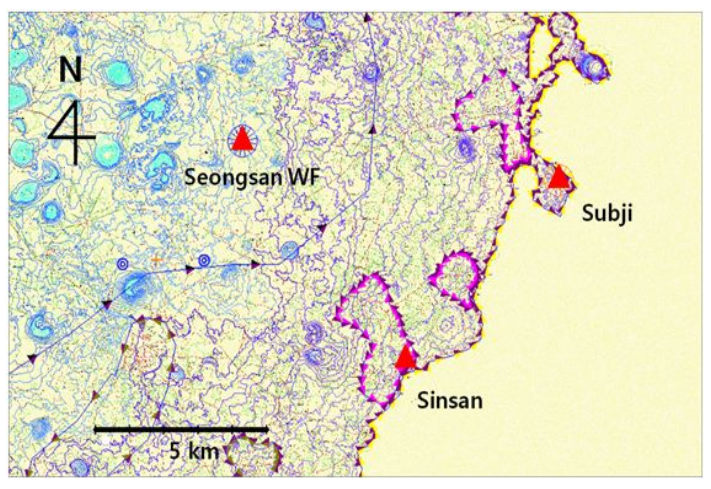

Fig. 2 Roughness map

In this investigation, the 30-year hourly wind data at Subji is predicted using MCP technique. Then each year's CF at Seongsan is obtained by running WAsP module of WindPRO based on each year's the Wind Statistics at Subji. Both the coefficients of variations and the ranges of variations are calculated from annual CFs to clarify inter-annul variations in $\mathrm{CF}$.

\section{Results and discussion}

\subsection{Wind conditions at measurement and reference sites}

The wind data at measurement site of Subji and reference site of Sinsan was analyzed to clarify wind characteristics at the two sites. Figure 3 displays Weibull distribution at $30 \mathrm{~m}$ above ground level at Subji site. Two parameters of Weibull distribution were $7.39 \mathrm{~m} / \mathrm{s}$ for scale parameter and 1.90 for shape parameter, respectively. The annual average wind speed was $6.57 \mathrm{~m} / \mathrm{s}$. 


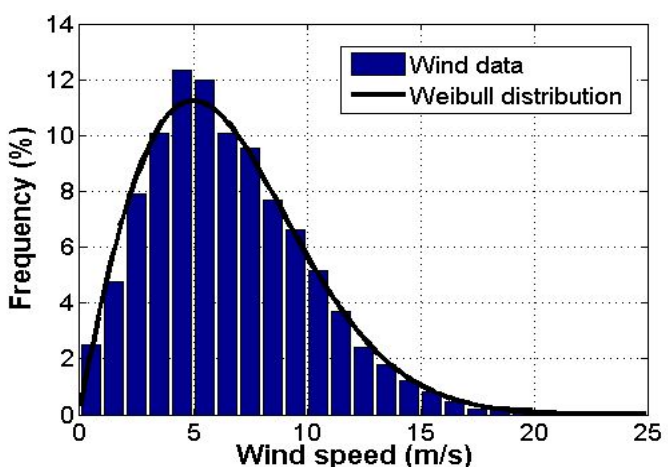

Fig. 3 Weibull distribution at $30 \mathrm{~m}$ above ground level at Subji

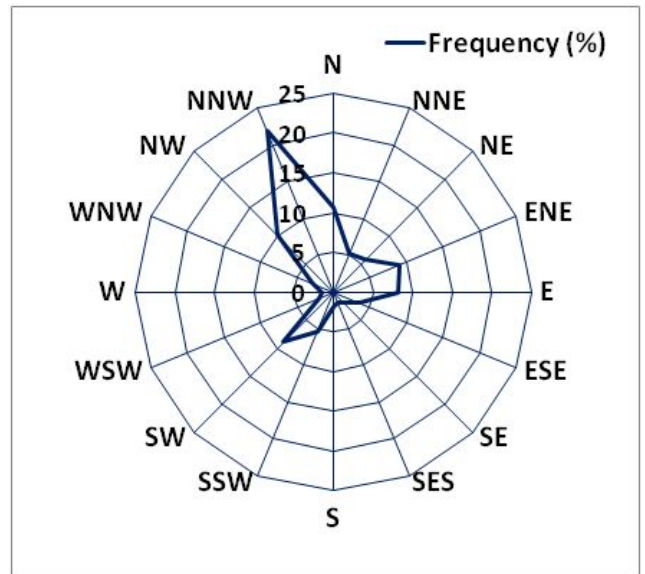

Fig. 4 Wind rose at $30 \mathrm{~m}$ above ground level at Subji

Wind rose at $30 \mathrm{~m}$ above ground level at Subji site is shown in Figure 4. Prevailing wind direction is from the north-north-west, which accounts for $21.9 \%$ of total time. The wind rarely blew from the west and the south.

Figure 5 represents inter-annual variations in wind speed and wind power density for 30 years at $10 \mathrm{~m}$ above ground level at Sinsan site. It can be seen that fluctuation in yearly average wind speeds and wind power density occurs at the site. Also wind speed and wind power density averaged over 30 years were $3.1 \mathrm{~m} / \mathrm{s}$ and $38.7 \mathrm{~W} / \mathrm{m}^{2}$, respectively. The yearly average wind speed and wind power density had random trend without any increasing or decreasing trends.

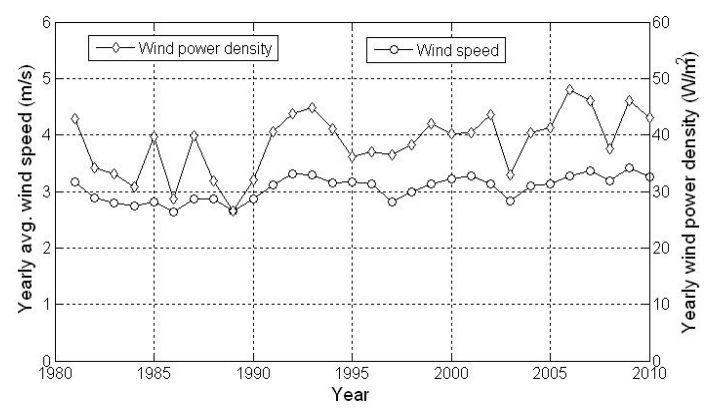

Fig. 5 Inter-annual variations in wind speed and wind power density at $10 \mathrm{~m}$ above ground level at Sinsan

\subsection{Application of matrix method of MCP technique}

MCP technique is widely used for estimating long-term wind statistic at a target site having the short-term wind data based on the long-term wind data at a more or less nearby site, that is, the reference site. The long-term wind data at a target site is predicted from the transfer model derived from concurrent wind data at the two sites.

WindPRO has four types of MCP modules that are Regression, Matrix, Weibull Scale and Wind Index. The Regression and Matrix methods were recommended ${ }^{11)}$ in case the wind data was available as high quality and detailed time series at both the measurement and the reference sites. In this study, since the wind data at Sinsan and Subji met the requirements, Regression and Matrix methods were applied to predict long-term wind data at Subji. The wind speed data predicted by means of Regression and Matrix methods was compared with the measured wind speed data. The correlation 
coefficient was derived from the comparison. The correlation coefficient on the basis of Regression method was about $74 \%$, which was almost the same as that based on Matrix method. Meanwhile, it was reported that Matrix method was better to estimate long-term wind data more accurately in Jeju than Regression method. ${ }^{12)}$ Accordingly Matrix method was adopted in this study.

Figure 6 shows an example of concurrent wind speed data at Subji and Sinsan sites. Although there is difference in values of wind speeds between the two sites, two types of wind speeds have a similar pattern in shape with elapsing time.

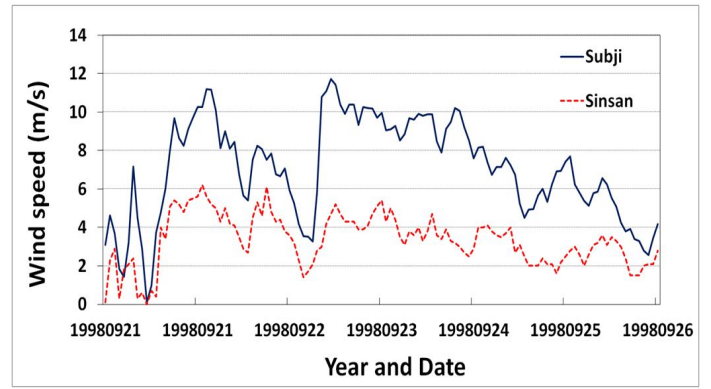

Fig. 6 An example of concurrent wind speed data at Subji and Sinsan sites

The scatter plot was obtained from the measured wind speed data at the two sites, which is shown in Figure 7. The correlation coefficient was $81.4 \%$, which is good for applying MCP technique.9)

The 30-year wind data at Subji was predicted by running Matrix MCP module. The predicted wind speed data for the year 1998 was compared with the measured wind speed data. The result is represented in Figure 8. The correlation coefficient between the two was $73.6 \%$, which was considered to be acceptable."

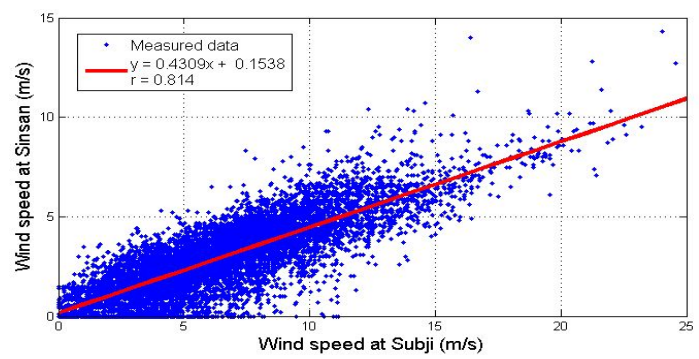

Fig. 7 Scatter plot of measured wind speed data at Sinsan and Subji sites

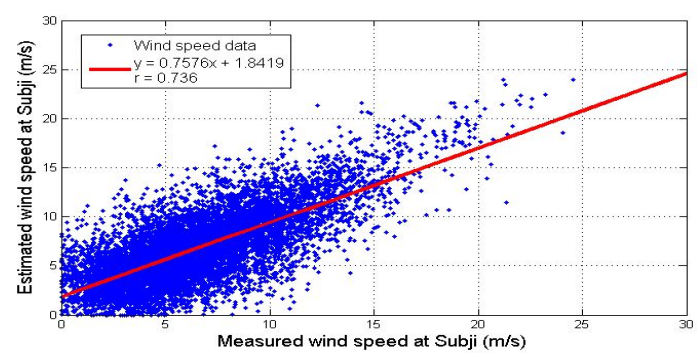

Fig. 8 Scatter plot of the measured and the estimated wind speed data at Subji sites

Each year's wind data was extracted from the predicted 30-year hourly wind data set. Then each year's wind data was input into the WAsP interface module of WindPRO to create the Wind Statistics at Subji, which was used for calculating each year's CF at Seongsan. Though Seongsan is about $10 \mathrm{~km}$ away from Subji, it was considered that the Wind Statistics of Subji could be used in Seongsan because the Wind Statistics created by running WAsP module is available within a maximum radius of $100 \mathrm{~km}$ from the original site. Although the height of the met mast at Subji was different from the $78 \mathrm{~m}$-hub height of VESTAS V-80 turbine at Seongsan, the error caused by wind shear extrapolation was neglected because the error rate of each year was considered to be the same, and the purpose of this investigation was to 
clarify inter-annual variations in wind speed and CF at Seongsan, not to clarify wind speed and $\mathrm{CF}$ themselves.

\subsection{Inter-annual variation in $\mathrm{CF}$ at Seongsan wind farm}

By running the WAsP interface module, annual average wind speed and $\mathrm{CF}$ can be obtained. Since VESTAS V-80 2 MW wind turbines are being operated in Seongsan wind farm, the same type of wind turbine was used for calculating $\mathrm{CF}$.

Figure 9 shows estimated variability of normalized annual average wind speed and normalized annual $\mathrm{CF}$ at Seongsan wind farm. It is clear that both the yearly average wind speed and the CF vary year by year. The CF increases with an increase of annual average wind speed. The annual $\mathrm{CF}$ for Seongsan wind farm was estimated to vary within about $\pm 4 \%$. Also, it was predicted that the fluctuation of the annual average wind speed at the turbine hub height of $78 \mathrm{~m}$ was in the range between $\pm 0.5 \mathrm{~m} / \mathrm{s}$.

In order to quantify variability in the $\mathrm{CF}$, the coefficient of variation, $\mathrm{CV}$, and the range of variation, $\mathrm{RV}$, were calculated by the following equations:

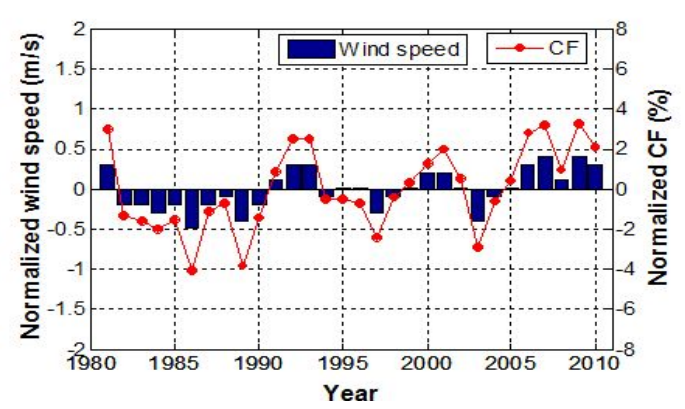

Fig. 9 Predicted variability of normalized annual average wind speed and normalized annual CF at Seongsan wind farm

$$
\begin{aligned}
& C V=\frac{\sigma}{\bar{y}} 100 \% \\
& R V=\frac{\bar{V}_{\max } \text { or } \bar{V}_{\min }-\bar{y}}{\bar{y}} 100 \%
\end{aligned}
$$

where, $\sigma$ is the standard deviation for yearly average wind speeds and $\bar{y}$ is the wind speed averaged over 30 years. $\bar{V}_{\max }$ and $\bar{V}_{\min }$ are the maximum and the minimum of yearly average wind speeds, respectively.

The CV and the RV are listed in Table 1. The CV and the RV for the 30-year CFs at Seongsan wind farm were estimated to be $8.3 \%$ and $-16.5 \% \sim 13.2 \%$, respectively. Considering that the yearly average wind speed generally varies within $\pm 10 \%$ of the long-term mean, which results in variation of $\pm 30 \%$ in wind power density ${ }^{13)}$, the $\mathrm{RV}$ and the $\mathrm{CV}$ for those at Seongsan wind farm are slightly small.

For the comparative study, the $\mathrm{CV}$ and the $\mathrm{RV}$ for the $\mathrm{CF}$ in the United Kingdom were introduced ${ }^{4)}$, which are also presented in Table 1. It can be seen that the CV and the RV for the CF in Seongsan wind farm are slightly smaller than those in the United Kingdom. The result shows that Seongsan wind farm is a normal one for inter-annual variation in wind speed and $\mathrm{CF}$.

Table 1. Coefficient of variation, CV, and range of variation, RV

\begin{tabular}{|c|c|c|}
\hline Items & CV (\%) & RV (\%) \\
\hline Average wind speed & 4.0 & $-7.6 \sim 6.5$ \\
\hline Wind power density & 9.6 & $-20.2 \sim 16.0$ \\
\hline CF & 8.3 & $-16.5 \sim 13.2$ \\
\hline $\begin{array}{c}\text { CF in the United } \\
\text { Kingdom }\end{array}$ & 9.5 & $-19.1 \sim 21.3$ \\
\hline
\end{tabular}

* CF: capacity factor

한국태양에너지학회 논문집 Vol. 32, No. 6, 2012 


\section{Conclusions}

Using MCP technique provided in WindPRO software, annual average wind speeds and $\mathrm{CFs}$ in Seongsan wind farm were predicted to clarify variation of the wind. The VESTAS $\mathrm{V}-802 \mathrm{MW}$ wind turbine was used for calculating the CFs. The results are as follows.

(1) The CV and the RV for the 30-year $\mathrm{CFs}$ at Seongsan wind farm were estimated to be $8.3 \%$ and $-16.5 \% \sim 13.2 \%$, respectively.

(2) Seongsan wind farm was estimated to be normal for inter-annual variation in wind speed and $\mathrm{CF}$.

(3) It was estimated that the annual $\mathrm{CF}$ and the annual average wind speed for Seongsan wind farm varied within about $\pm 4 \%$ and $\pm 0.5 \mathrm{~m} / \mathrm{s}$, respectively.

\section{ACKNOWLEDGEMENTS}

This work was supported by the Human Resources Development of the Korea Institute of Energy Technology Evaluation and Planning (KETEP) grant funded by the Korea government Ministry of Knowledge Economy.

(NO. 20094020200020)

\section{References}

1. IEA Wind. IEA Wind 2010 Annual Report. 2011.

2. BTM Consult ApS. http://www.btm.dk.

3. Weisser D, Foxon TJ. Implications of seasonal and diurnal variations of wind velocity for power output estimation of a turbine: a case study of Grenada. International Journal of Energy Research, Vol. 27, pp.
1165-1179, 2003.

4. Sinden G. Characteristics of the UK wind resource : long-term patterns and relationship to electricity demand. Energy Policy, Vol. 35, pp. 112-127, 2007.

5. Yoreley CS, Jorge XB. Statistical analysis of wind power in the region of Veracruz (Mexico). Renewable Energy, Vol. 34, pp. 1628-1634, 2009.

6. Erich Hau. Wind Trubines - Fundamentals, Technologies, Application, Economics. Springer: Verlag Berlin Heidelberg, pp. 464-468, 2006.

7. Ko KN, Kim KB, Huh JC. Variations of wind speed in time on Jeju Island, Korea. Energy, Vol. 35, pp. 3381-3387, 2010.

8. Ko KN, Kim KB, Huh JC. Characteristics of wind variations on Jeju Island, Korea. International Journal of Energy Research, Vol. 34, pp. 36-45, 2010.

9. EMD International $\mathrm{A} / \mathrm{S}$. WindPRO 2.5 User Guide. 2006.

10. Manwell JF, Mcgowan JG, Rogers AL. Wind energy explained. Wiley: p.28, 2010.

11. Thpgersen ML, Motta M, Sprensen T, Nielsen P. Measure-Correlate -Predict method: case studies and software implementation. European Wind Energy Conference and Exhibition, Milan(IT), 7-10 May 2007.

12. Seo HS, Kyong NH, Kim HG. Analysis on wind characteristics for offshore wind structure turbine design at Waljeong, Jejudo. The Wind Engineering Institute of Korea, Vol.14, No.3, pp. 161-167, 2010.

13. Nakao T, Sugiya T, Kato H, Kobayashi Y. Characteristics on the wind variability for the planning of wind turbine generation systems. Journal of the Japan Wind Energy Association, Vol. 28, No. 4, pp. 95-99, 2004. 